\title{
MENGEMBANGKAN AGRIBISNIS SKALA RUMAH TANGGA YANG RAMAH LINGKUNGAN PADA LAHAN GAMBUT MELALUI USAHATANI TANAMAN SAGU
}

\section{DEVELOP ENVIRONMENTALLY FRIENDLY HOUSEHOLD SCALE AGRIBUSINESS ON PEATLAND THROUGH THE SAGO FARMING}

\author{
Suharno \\ Staf Pengajar Program Studi Agribisnis, Fakultas Pertanian, Universitas Palangka Raya \\ e-mail: suharno_unpar@yahoo.com
}

\begin{abstract}
ABSTRAK
Sagu (Metroxylon spp.) merupakan salah satu tumbuhan keluarga palmae yang menghasilkan pati, yang tumbuh secara alami terutama di daerah dataran rendah atau rawa. Semakin basah tanahnya, tanaman sagu justru akan tumbuh semakin subur, sehingga cocok untuk dikembangkan pada ekosistem rawa dan gambut. Studi ini bertujuan untuk mengkaji kelayakan teknis dan kelayakan ekonomis budidaya tanaman sagu pada lahan gambut. Kajian didasarkan pada data dan informasi sekunder dari berbagai literatur. Kelayakan teknis diuraikan secara deksriptif tentang teknis budidaya tamanan sagu pada lahan gambut, sedangkan kelayakan ekonomis diukur dengan nilai $N P V, B / C$ Ratio, IRR dan Payback Period. Hasil kajian menunjukkan bahwa sesuai dengan karakteristiknya sebagai tanaman pada ekosistem rawa, secara teknis tanaman sagu cocok diusahakan pada lahan gambut. Potensi produksi sagu dapat mencapai $20-40$ ton pati kering/ha per tahun. Pati sagu dapat digunakan sebagai bahan pangan potensial, bahan pakan ternak, bahan bakar hayati (bioetanol), dan bahan baku industri lainnya. Secara ekonomis, hasil analisis kelayakan menunjukkan bahwa usahatani tanaman sagu layak diusahakan, yaitu dengan nilai NPV sebesar Rp 284.969,03; B/C Ratio sebesar 4,84; IRR sebesar 31,31\% dan masa kembali modal (Payback Period) pada tahun ke-10, atau tahun kedua setelah tanaman menghasilkan.
\end{abstract}

Kata kunci: Analisis kelayakan, lahan gambut, sagu

\section{ABSTRACT}

Sago (Metroxylon spp.) is one of the palmae family plants that produce starch, which grows naturally especially in lowland or swamp areas with abundant water sources. The more wet of the the soil, sago plants will grow even more fertile. This study aims to analize the technical viability and economic feasibility of sago cultivation on peatlands. The study is based on secondary data and information from various literatures. Technical feasibility is described descriptively on the technical cultivation of sago on peatlands, whereas economic feasibility is measured by NPV, B/C Ratio, IRR and Payback Period values. The results of the study indicate that in accordance with its characteristics as a crop in the swamp ecosystem, technically sago plant is suitable to be cultivated on peatlands. The potential for sago production can reach 20-40 tons of dried starch/ha per year. Economically, the result of feasibility analysis shows that sago cultivation is feasible to be cultivated, that is with NPV value of Rp 284,969.03; B/C Ratio of 4.84; IRR of $31.31 \%$ and the return on capital (Payback Period) in the 10th year, or the second year after the plant produces. 


\section{PENDAHULUAN}

Lahan gambut adalah lahan yang jenis tanahnya didominasi oleh tanah gambut. Tanah gambut adalah jenis tanah yang terbentuk dari material atau bahan organik yang tertimbun secara alami dalam keadaan basah berlebihan, bersifat tidak mampat dan tidak atau hanya sedikit mengalami perombakan. Gambut terbentuk oleh lingkungan yang khas, yaitu rawa atau suasana genangan yang terjadi hampir sepanjang tahun. Kondisi langka udara (anaerob) akibat keadaan hidro-topografi berupa genangan, ayunan pasang surut, atau keadaan yang selalu basah telah mencegah aktivitas mikroorganisme yang diperlukan dalam perombakan, (Noor, 2001). Daerah Indonesia terdapat sekitar 20,1 juta hektar lahan gambut tropika dan merupakan negara yang memiliki lahan gambut tropika terbesar di dunia. Sampai awal dekade 1970-an, lahan-lahan gambut sebagai bagian dari ekosistem rawa umumnya dipandang sebagai lahan tak berguna (waste land) dan sebagai lingkungan yang tidak mempunyai daya tarik dan tidak menjanjikan. Sesungguhnya lahan gambut merupakan sumberdaya yang sangat penting karena mempunyai potensi pemanfaatan yang beragam (Radjagukguk, 2000; Maas, 2002).

Salah satu jenis tanaman yang dapat dikembangkan pada ekosistem rawa dan gambut yang memiliki nilai ekonomi tinggi adalah tanaman sagu. Sagu (Metroxylon spp.) merupakan salah satu tumbuhan keluarga palmae yang menghasilkan pati, yang tumbuh secara alami terutama di daerah dataran rendah atau rawa dengan sumber air melimpah. Menurut Kementerian Pertanian (2013), sagu merupakan tanaman asli Indonesia, karena ditemukan keragamannya sangat tinggi dan tumbuh mendominasi di kawasan Timur Indonesia. Populasi sagu terkonsentrasi di Indonesia dan Papua Nugini. Di Indonesia, sentra pertanaman sagu tersebar di Papua, Papua Barat, Maluku, Maluku Utara, Riau, Sulawesi, dan Kalimantan. Data luas pertanaman sagu, baik yang sudah dibudidaya atau berupa hamparan hutan/liar belum begitu akurat. Menurut Nurhaedah (2015) di Indonesia terdapat sekitar 1,25 juta hektar lahan sagu atau 50\% dari lahan sagu dunia seluas 2.5 juta hektar.

Potensi produksi sagu dapat mencapai 20-40 ton pati kering/haper tahun apabila dibudidayakan dengan baik. Namun menurut Asmono (2016), produktivitas kebun sagu yang dikelola oleh PT. Sampoerna Agro Tbk. rata-rata produktivitras diperoleh 8,5 ton tepung kering per hektar/tahun dan ditargetkan bisa naik menjadi 12 ton per hektar/tahun. Sementara menurut Stanton (1986), sebagai dikutip oleh Timisela (2006), pada keadaan lingkungan yang baik, tanaman sagu mampu berproduksi 15-25 ton/hektar tepung sagu kering, terbaik bila dibandingkan dengan tanaman penghasil pangan yang lain.

Menurut Subiyanto (2016), tanaman sagu sangat cocok diusahakan pada lahan basah karena sagu senang tumbuh di tanah basah dan air. Semakin basah tanahnya, justru sagu akan tumbuh semakin subur dan tidak akan mati. Budidaya tanaman sagu membawa dampak sangat positif, karena secara ekologis sagu memiliki kemampuan menyimpan air, sehingga cocok digunakan dalam upaya memulihkan/merestorasi lahan gambut yang rusak. Penggunaan tanaman sagu untuk memulihkan lahan gambut sejalan dengan Peraturan Presiden Nomor 1 Tahun 2016 tentang Badan Restorasi Gambut (BRG). Restorasi lahan gambut sangat penting untuk dilaksanakan, dan tanaman sagu bisa membantu restorasi tersebut karena bisa tumbuh dengan baik di 
genangan air, sehingga cocok ditanam di lahan gambut. Pemanfaatan lahan gambut untuk budidaya tanaman sagu atau rumbia memiliki dampak sangat positif, bukan hanya secara ekologis, namun juga secara ekonomis, karena budi daya sagu di lahan gambut memilik pola penanaman sangat sederhana, tanpa membutuhkan perawatan khusus.

Usaha budidaya sagu memang termasuk investasi jangka panjang karena tidak boleh ditebang untuk diambil patinya sebelum berusia delapan tahun. Pohon jenis ini bisa beregenerasi secara alamiah seperti tanaman pisang, sehingga ekosistem lahan gambut bakal terus terjaga (Nazir, 2016). Selain itu, tanaman sagu dapat menyerap $\mathrm{CO}_{2}$ dalam jumlah besar sehingga dapat membantu mengatasi ancaman pemanasan global. Lingkungan yang ditumbuhi sagu akan terjaga dari kerusakan lingkungan karena sagu mempunyai anakan yang banyak dan tidak perlu diremajakan sehingga dapat mencegah penurunan permukaan tanah gambut atau subsidensi (Kementerian Pertanian, 2014).

Tanaman sagu juga memiliki banyak aspek positif untuk kesejahteraan masyarakat sekitar khususnya dan nasional pada umum. Dari aspek lingkungan, vegetasi sagu berfungsi untuk membersihkan udara dan menghasilkan oksigen yang sangat diperlukan makhluk hidup. Selain itu,dikenal sangat bermanfaat bagi manusia antara lain sebagai bahan pangan potensial, bahan pakan ternak, bahan bakar hayati (bioetanol), dan bahan baku industri. Industri yang berbahan baku sagu ini sangat beragam antara lain industri gula cair, penyedap makanan, perekat (lem), tekstil, dan industri makanan seperti mie, tepung, kue kering/basah. Dari sagu juga dapat dihasilkan industri turunannya antara lain asam laktat, destrin, maltosa, fruktosa, cianol yang berfungsi dalam pembuatan pestisida (nabati), film, tekstil, kertas, kayu lapis, kosmetik, dan makanan. Ampas dari pengolahan sagu dapat berfungsi sebagai media jamur, dan hardboard (Nazir, 2016; Yoandestina, 2014).

Selain efisien dalam memproduksi karbohidrat, keunggulan lain dari tanaman sagu adalah: 1). Secara ekonomi dan budaya dapat diterima oleh masyarakat; 2).Ramah lingkungan dan mampu berproduksi memadai pada lahan gambut dangkal maupun tanah mineral basah tanpa input produksi yang berbasis kimiawi; 3). Membentuk agroforestry yang stabil (Timisela, 2006). Sementara menurut Nurhaedah (2015), ada beberapa peluang untuk mengembangkan usahatani sagu bagi masyarakat, yaitu: 1). Adanya budaya makan sagu bagi beberapa suku di Indonesia; 2). Banyak terdapat lahan rawa yang sesuai untuk tanaman sagu; 3). Sagu memiliki banyak manfaat.

Berdasarkan latar belakang di atas, perlu dilakukan suatu kajian tentang potensi pengembangan agribisnis sagu pada lahan gambut yang bertujuan untuk: 1). Mengkaji teknis budidaya tanaman sagu pada lahan gambut; 2). Menganalisis kelayakan ekonomis dari usahatani tanaman sagu yang diusahakan pada lahan gambut.

\section{METODE PENELITIAN}

Studi ini merupakan kajian data sekunder, dimana data dan irformasi yang diperlukan diperoleh dari berbagai literatur yang relevan yang diperoleh dari berbagai pusat sumber informasi, baik melalui internet, perpustakaan, maupun koleksi pustaka milik pribadi. Deskripsi teknis budidaya tanaman sagu terutama diambil dari Lampiran Peraturan Menteri Pertanian Republik Indonesia Nomor: 134/Permentan/Ot.140/12/2013 tentang Pedoman Budidaya Sagu (Metroxylon Spp) yang baik, serta dari berbagai literatur yang relevan.

Analisis $\begin{gathered}\text { kelayakan usahatani } \\ \text { dilakukan }\end{gathered}$
dengan
menghitung nilai Net Present Value $(N P V)$,


Benefit and Cost Ratio (B/C Ratio), Internal Rate of Return (IRR), dan masa kembali modal (Payback Period), dengan kriteria kelayakan proyek sebagai berikut: $\mathrm{NPV}>0$; B/C Ratio > 1; IRR > diskon factor; Payback Period < umur proyek.

\section{HASIL DAN PEMBAHASAN}

\section{Teknis Budidaya Tanaman Sagu}

Pengembangan perkebunan sagu pada prinsipnya tidak berbeda dengan pengembangan tanaman tahunan atau tanaman perkebunan lainnya. Pemilihan lokasi atau tempat usaha pengembangan tanaman menjadi hal penting yang harus dipertimbangkan. Kesesuaian lahan dan iklim penting untuk dilakukan pada awal persiapan pengembangan. Selain itu, persiapan sumber dan pengadaan bibit serta pengaturan sistem tanam dan lokasi merupakan satu paket terintegrasi dalam pengembangan sagu. Berdasarkan Lapiran Peraturan Menteri Pertanian Republik Indonesia Nomor: 134/Permentan/Ot.140/12/2013 tentang Pedoman Budidaya Sagu (Metroxylon Spp) Yang Baik, prinsip budidaya tanaman sagu adalah sebagai berikut:

\section{1) Persyaratan Tumbuh Tanaman a. Iklim}

Tanaman sagu memerlukan ketersediaan air yang cukup semasa pertumbuhannya. Curah hujan optimal berkisar antara2.000-4.000 mm/tahun dan tersebar merata sepanjang tahun. Jumlah bulan basah berkisar antara 4-9 bulan berturut-turut, dengan bulan kering tidak lebih dari 2 bulan berturut-turut. Meskipun tanaman sagu dapat hidup dengan baik pada lahan yang tergenang, namun tidak terlalu baik jika tergenang permanen. Hasil penelitian dan informasi dari berbagai sumber menyatakan bahwa genangan (tidak permanen) setinggi $<50 \mathrm{~cm}$ yang terbaik. Suhu optimum berkisar antara $24,5^{\circ} \mathrm{C}-29^{\circ} \mathrm{C}$ dengan kelembaban ideal antara $40-60 \%$ serta tertinggi $90 \%$.
Tanaman sagu sebagaimana tanaman palma umumnya memerlukan intensitas dan lama penyinaran yang cukup tinggi. Persyaratan tumbuh dari segi iklim ini secara umum sesuai dengan hampir seluruh wilayah di Indonesia yang berada di kawasan tropis dan memiliki banyak rawa, dan cocok untuk dikembangkan pada lahan gambut.

\section{b. Lahan dan Jenis Tanah}

Topografi umum dari kawasan pertanaman sagu dari jenis Metroxylon spp. yaitu datar, landai hingga bergelombang. Tipe lahan rawa dan gambut atau sepanjang pinggiran sungai merupakan tempat tumbuh ideal bagi jenis tanaman ini. Kawasan sagu yang mendapat genangan periodik atau pengaruh pasang surut atau penataan sistem drainase yang baik dapat mendukung pertumbuhan tanaman yang baik. Pergantian air segar yangmasuk ke kawasan pertanaman sagu akan membawa beberapa unsur hara yang dibutuhkan tanaman sagu seperti Potassium, Fosfat, Kalsium, dan Magnesium.

Tanaman sagu dapat tumbuh dan berkembang hingga ketinggian $700 \mathrm{~m}$ di atas permukaan laut (dpl), tetapi ketinggian optimal yaitu <400 m dpl. Jenis tanah yang dibutuhkan sagu spektrumnya luas mulai dari tanah dengan komposisi liat $>70 \%$, dengan bahan organik $30 \%$ dan $\mathrm{pH}$ tanah 5.5-6.5, tetapi sagu masih bisa beradaptasi dengan kemasaman lebih tinggi. Jenis-jenis tanah yang sesuai untuk tananam sagu meliputi: jenis tanah liat kuning coklat atau hitam dengan kadar organik tinggi, tanah vulkanik, latosol, andosol, podsolik merah kuning, aluvial, histosol dan hidromorfik kelabu. Berdasarkan persyaratan tumbuh dari segi lahan dan jenis tanah tersebut, tanaman sagu dapat dikembangkan dengan baik pada lahan rawa dan gambut.

\section{2) Pemilihan dan Persiapan Lokasi}

Pemilihan lokasi menjadi hal penting dalam upaya pengembangan sagu. 
Lokasi sebaiknya mudah dijangkau, dan dilengkapi dengan prasarana penunjang produksi dan prasarana penunjang lainnya, seperti saluran drainase dan jalan usahatani. Persiapan lokasi pengembangan tanaman sagu kemungkinan besar berada di sekitar kawasan hutan sagu atau hutan alam. Menyiapkan kawasan seperti ini tidak terlalu berbeda dengan kegiatan pengembangan tanaman tahunan atau tanaman perkebunan lainnya. Secara garis besar persiapan lokasi pengembangan meliputi: 1). Pembersihan tanaman besar (pohon), semak/belukar, dan perdu; 2). Pembuatan dan pengaturan sistem drainase (karena lokasi budidaya di area rawa atau gambut), dimana pinggiran saluran tersebut sekaligus dapat digunakan sebagai jalan usahatani. Sistem drainase yang dibuat tidak memotong kubah gambut dan bertujuan menjaga kedalaman air tanah pada lahan gambut tidak lebih dari $50 \mathrm{~cm}$ dari permukaan tanah. Pembuatan saluran drainase ini bertujuan sebagai pembuangan air yang berlebihan, baik pada saat terjadi pasang maupun genangan karena hujan yang terlalu deras agar tidak terjadi genangan permanen.

\section{3) Penanaman}

\section{a. Penyiapan Bibit Tanaman}

Bibit atau bahan tanam sagu harus berasal dari jenis-jenis sagu unggul, terutama dari potensi produksi pati yang tinggi. Jenis sagu yang sudahterkenal dengan tingkat produksi tinggi antara lain Molat, Tuni, Ihur, Makanaru, dan Rotan (di Maluku). Jenis sagu di Papua antar merupakan jenis yang sama. Perbanyakan tanaman sagu umumnya dengan anakan (vegetatif), tetapi tidak semua anakan dapat dijadikan sebagai sumberperbanyakan.

\section{b. Persiapan Penanaman}

\section{- Pengaturan Jarak Tanam, Pengajiran dan Pembuatan Lobang Tanam}

Sagu ditanam dengan jarak yang bervariasi mulai dari $8 \mathrm{~m} \times 8 \mathrm{~m}$; $9 \mathrm{~m} \times 9 \mathrm{~m}$ atau $10 \mathrm{~m} \times 10 \mathrm{~m}$ tergantung varietasnya dengan sistem tanam segi empat, sehingga jumlah populasi per hektar berkisar antara
130-150 pohon. Agar tanaman terlihat rapih dan teratur, maka sebelum membuat lobang tanam perlu dilakukan pengajiran pada titik-titik calon lobang tanam sesuai dengan jarak tanam yang ditetapkan. Pengajiran dapat menggunakan bilah bambu atau bahan lainnya yang cukup kuat. Bahan ajir yang kuat dapat sekaligus digunakan sebagai penahan bibit yang baru ditanam. Lobang tanam dibuat pada setiap ajir dengan ukuran $30 \mathrm{~cm} \times 30 \mathrm{~cm} \times 30 \mathrm{~cm}$.

\section{- Penanaman Bibit}

Bibit yang telah dipersiapkan di pesemaian dibawa ke lahan penanam. Daun bibit dipangkas $(30-50 \mathrm{~cm}$ dari banir). Bibit yang telah siap ditanam diletakkan di pinggir lobang tanam. Jika pesemaian menggunakan polibag, sebelum ditanam polibagnya harus dibuang dengan cara merobek polibag dengan hati-hati agar tanah yang menempel pada akar bibit tidak terlalu banyak yang terlepas.

Bibit dimasukkan ke dalam lobang tanam secara tegak lurus, kemudian ditimbun dengan tanah bekas galian lobang tanam dan agak dipadatkan agar bibit tidak mudah roboh dan sebaiknya diberi penahan, diletakkan menyilang di bagian depan dari batang bibit setelah ditimbun dengan tanah sebatasleher bibit. Tingkat keberhasilan tanaman muda di areal pertanaman sangat dipengaruhi oleh ketersediaan air. Oleh karenanya dianjurkan penanaman dilakukan saat musim hujan atau tergantung pada ketersediaan air di lokasi pertanaman. Salah satu kelebihan dari tanaman sagu yaitu penanaman hanya dilakukan sekali dan tidak ada istilah "peremajaan" tetapi yang harus dilakukan adalah pengurangan atau pengelolaan anakan per rumpun. Jadi, budidaya sagu merupakan usahatani paling "efisien" dibanding tanaman tahunan/perkebunan lainnya.

\section{4) Pemeliharaan Tanaman}

a. Penyulaman

Penyulaman yaitu kegiatan menanam kembali tanaman sagu pada rumpun sagu yang mati karena kurang 
beradaptasi dengan lingkungan di lapangan atau terserang hama dan penyakit. Bibit atau bahan tanam yang digunakan untuk penyulaman harus menggunakan varietas yang sama dengan bibit yang ditanam sebelumnya. Kegiatan penyulaman sebaiknya dilakukan pada musim hujan karena permukaan air tanah dapat tinggi, sehingga bibit dapat ditanam pada lubang tanam yang ketersediaan airnya tercukupi. Selain itu penyulaman pada musim hujan tanaman dapat mengurangi transpirasi yang terjadi.

\section{b. Pemupukan}

Pohon sagu yang tumbuh secara alami pada kawasan lahan gambut dan pasang surut, meskipun tanpa pemupukan dan perawatan tampak cukup baik. Namun apabila tanaman sagu dibudidayakan secara intensif, untuk menjamin pertumbuhan yang optimal dan produktivitas yang tinggi harus dilakukan pemupukan. Jenis pupuk utama yang diberikan untuk tanaman sagu adalah jenis pupuk yang mengandung unsur-unsur nitrogen $(\mathrm{N})$ dalam bentuk Urea, phosfor (P) dalam bentuk SP-36, Kalium (K) dalam $\mathrm{KCl}$ dan Magnesium $(\mathrm{Mg})$ dalam bentuk Kieserit. Dosis pemupukan yang dianjurkan seperti terlihat pada Tabel 1.

Pemupukan dilakukan dengan membenamkan pupuk dalam tanah, agar tidak terbawa air sebelum terabsorbsi oleh akar tanaman lahan yang berada di daerah rawa/dataran rendah dan pasang surut yang sering yang terjadi luapan air. Pemupukan dilaksanakan secara melingkar di sekeliling rumpun atau secara lokal di daun sisi rumpun pada jarak sejauh pertengahan antara ujung tajuk dengan pohon/rumpun sagu. Waktu pemupukan untuk tanaman sagu muda adalah sampai 1 tahun menjelang panen, pemupukan dilakukan 12 kali setahun. Pemupukan sekali setahun, dilakukan pada awal musim hujan. Sedangkan untuk pemupukan dua kali setahun dilakukan pada awal dan akhir musim hujan, masing-masing dengan $1 / 2$ dosis.

Tabel 1. Dosis Pupuk pada Budidaya Sagu (Per Pohon)

\begin{tabular}{cccccc}
\hline $\begin{array}{c}\text { Umur Tanaman } \\
(\text { th })\end{array}$ & $\begin{array}{c}\text { Urea } \\
(\mathrm{g})\end{array}$ & $\begin{array}{c}\text { Phosphat } \\
\text { Alam }(\mathrm{g})\end{array}$ & $\begin{array}{c}\text { TSP/SP-36 } \\
(\mathrm{g})\end{array}$ & $\begin{array}{c}\text { KCL } \\
(\mathrm{g})\end{array}$ & $\begin{array}{c}\text { Kieserite } \\
(\mathrm{mg})\end{array}$ \\
\hline 0 & 0 & 300 & 0 & 0 & 0 \\
1 & 100 & 0 & 100 & 50 & 0 \\
2 & 150 & 0 & 150 & 100 & 0 \\
3 & 200 & 0 & 200 & 150 & 30 \\
4 & 250 & 250 & 0 & 250 & 40 \\
5 & 300 & 0 & 300 & 250 & 50 \\
6 & 400 & 400 & 0 & 400 & 80 \\
7 & 500 & 0 & 500 & 500 & 100 \\
8 & 500 & 500 & 0 & 600 & 120 \\
$\geq 9$ & 500 & 0 & 500 & 700 & 140 \\
\hline
\end{tabular}

Sumber: http://budidayanews.blogspot.co.id/2011/06/budidaya-tanaman-sagu.html

\section{c. Penjarangan Anakan}

Penjarangan anakan sagu berfungsi untuk mengurangi persaingan pertumbuhan antar anakan untuk meningkatkan produktivitasnya, dengan mengeluarkan anakan tidak produktif dan mengurangi anakan yang kurang produktif. Tanpa penjarangan anakan pertumbuhan tanaman sagu akan lambat, kadar patinya rendah, pemeliharaan tanaman khususnya pemupukan tidak efisien dan pemanenan sulit dilakukan. Penjarangan anakan dilakukan dengan mengangkat anakan sampai ke akarnya (Jayanti, 2011). 


\section{d. Pengendalian Gulma.}

Gulma merupakan tumbuhan yang keberadaannya dapat mengganggu tanaman lain pada tingkatan jumlah tertentu. Pertumbuhan gulma yang sangat cepat daripada tanaman sagu dapat menghambat pertumbuhan sagu, hal ini disebabkan adanya persaingan dalam mendapatkan unsur hara, sinar matahari, air, dan ruang tumbuh. Pengendalian gulma dapat dilakukan secara manual dan secara kimia. Kedua cara pengendalian gulma ini memiliki keuntungan dan kerugian dari segi biaya, waktu, dan pengaruhnya terhadap pertumbuhan sagu. Pengendalian gulma secara manual yang dilakukan dengan cara penebasan. Prosedur penebasan yaitu lebar tebasan 1,5-2m pada lorong antar rumpun tanaman dan pada piringan dengan radius 1 meter dari rumpun. Penebasan gulma diusahakan sedekat mungkin dengan permukaan tanah. Rotasi pengendalian gulma secara manual dilakukan satu kali dalam satu tahun.

Pengendalian gulma secara kimia dilakukan dengan menggunakan herbisida yang disemprotkan pada gulma. Penyemprotan dilakukan pada gawangan dan piringan mati yaitu piringan yang tidak terdapat tanaman sagu. Rotasi pengendalian gulma secara kimia dilakukan dua kali dalam satu tahun. Herbisida yang digunakan yaitu herbisida kontak dengan bahan aktif paraquat berbentuk cairan dengan dosis 1,5 liter/ha.

\section{e. Pengendalian Hama dan Penyakit Tanaman}

Pada tanaman sagu terdapat hama dan penyakit yang dapat mengurangi hasil panen. Beberapa jenis hama dan penyakit adalah sebagai berikut:

\section{- Kumbang (Oryctes rhinoceros sp.)}

Gejala dari serangan hama ini adalah terdapat lubang pada pucuk daun bekas gerekan kumbang, setelah berkembang tampak terpotong seperti digunting dalam bentuk segitiga. Pengendalian dapat dilakukan secara mekanis dan biologis. Pengendalian secara mekanis adalah dengan cara pohon-pohon sagu yang mendapat serangan ditebang dan dibakar. Pengendalian secara biologis dapat dengan menggunakan musuh alami.

\section{- Kumbang sagu (Rhynchophorus sp)}

Ciri dari serangan hama ini adalah, serangan sekunder setelah kumbang oryctes biasanya meletakkan telur di luka bekas oryctes. Bila serangan terjadi pada titik tumbuh dapat menyebabkan kematian pohon. Pengendalian dapat dilakukan dengan cara mekanik dan biologis.

\section{- Ulat daun Artona (Artona catoxantha, Hamps atau Brachartona catoxantha)}

Ulat daun selain merusak daun pada sagu, juga menyerang pada daging buah, ulat daun ini menyerang jaringan dalam daun. Pengendalian pada ulat daun dapat dilakukan secara mekanik dan biologis.

\section{- Penyakit}

Penyakit yang biasanya terdapat pada tanaman sagu yaitubercak kuning yang disebabkan oleh cendawan Cercospora. Gejala dari penyakit ini yaitu daun berbercak-bercak coklat. Gejalanya adalah daun berbercak-bercak coklat dan dapat mengakibatkan seluruh daun berbercak-bercak kering atau berlubanglubang. Bila serangan cukup hebat, kanopi tanaman sagu nampak meranggas. Pengendalian penyakit pada tanaman sagu belum ada secara khusus, hanya pemakaian fungisida dan menjaga sanitasi lingkungan.

\section{5) Panen}

Karakter utama pohon sagu siap panen secara visual (langsung terlihat di kebun/hamparan) yaitu berdasarkan pada ukuran morfologi. Kriteria tersebut yaitu ukuran batang dan tinggi terbesar dalam satu rumpun dan jumlah daun di pucuk/mahkota yang berjumlah antara 3-4 pelepah, dan belum muncul bunga (bagian pucuk kelihatan membengkak). Keterlambatan panen (bunga pada pohon sagu telah mekar) menyebabkan penurunan rendemen pati yang sangat tinggi. Umur tanaman sagu siap panen berkisar antara 712 tahun tergantung dari varietas dan 
kondisi tanaman di lapangan. Pohon sagu yang siap panen berkisar antara 10-15 m, diameter $60-70 \mathrm{~cm}$, tebal kulit luar $10 \mathrm{~cm}$, dan tebal batang yang mengandung sagu sekitar 50-60 cm. Langkah-langkah pemanenan sagu adalah sebagai berikut: 1). Pembersihan untuk membuat jalan masuk ke rumpun dan pembersihan batang yang akan dipotong untuk memudahkan penebangan dan pengangkutan hasil tebangan; 2). Sagu dipotong sedekat mungkin dengan akarnya. Pemotongan menggunakan kampak atau mesin pemotong (gergaji mesin); 3). Batang dibersihkan dari pelepah dan sebagian ujung batangnya karena acinya rendah, sehingga tinggal gelondongan batang sagu sepanjang 6-15 meter. Gelondongan dipotong-potong sepanjang sekitar 1 meter yang disebut tual. Tujuan dari pembuatan tual ini adalah untuk memudahkan pengangkutan.

Pemanenan kedua dilakukan dengan jangka waktu \pm 2 tahun. Perkiraan produksi hasil yang paling mendekati kenyataan pada kondisi liar dengan produksi $40-60$ batang/ha/tahun, jumlah empulur 1 ton/batang, kandungan aci sagu $18,5 \%$, dapat diperkirakan hasil per hektar per tahun adalah 7-11 ton aci sagu kering. Secara teoritis, dari satu batang pohon sagu dapat dihasilkan $100-600 \mathrm{Kg}$ pati sagu kering. Rendemen total untuk pengolahan yang ideal adalah $15 \%$.

\section{Analisis Kelayakan Usahatani}

Investasi awal dalam
pengembangan sagu cukup mahal, karena masa Tanaman Belum Menghasilkan (TBM) itu panjang selama 10 tahun. Namun kalau sudah ditanam, sagu akan menjadi bisnis perkebunan yang abadi. Sedangkan tanaman kelapa sawit tumbuh selama 25 tahun, setelah itu ditebang, tanaman sagu tidak perlu melakukan itu. Memanen batang yang setiap ditebang akan terus muncul anakan. Anakan ini ditata rapi, maka rumpun ini akan terus menghasilkan sagu. Sehingga meskipun investasi awalnya mahal, tampaknya dari segi bisnis usaha budidaya tanaman sagu cukup menjanjikan, karena selain produktivitas yang cukup tinggi, diversifikasi pemanfaatan tepung sagu cukup luas, baik sebagai bahan pangan maupun sebagai bahan baku industri, termasuk sebagai bahan baku bahan bakar hayati (biofuel) berupa etanol.Yang lebih menarik dari segi bisnis adalah ternyata harga tepung sagu di pasaran cukup tinggi. Menurut Bambang Sukmananto (Direktur Utama Perhutani), di Papua, sagu dijual di kisaran Rp 5.000 hingga Rp 6.000 per kilogram, sedangkan biaya produksinya hanya separuhnya, meskipun masa menunggu sampai tanaman siap dipanen cukup lama, yaitu berkisar 7-12 tahun (Syakir dan Karmawaty, 2013).

Kriteria kelayakan usahatani diukur dengan menghitung besarnya Net Present Value (NPV), rasio manfaat dan biaya (benefit and cost ratio) ata $\mathrm{B} / \mathrm{C}$ ratio, internal rate of return (IRR)dan periode kembali modal (payback periode). Asumsi yang digunakan dalam analisis kelayakan ini adalah sebagai berikut: 1). Usahatani tanaman sagu dilakukan petani secara mandiri dengan luas kebun 2 ha/petani; 2). Populasi tanaman/ha 120 batang; 3). Investasi awal sebesar Rp 23.689.000; 4). Tanaman siap panen pada umur 9 tahun; 5). Jumlah tanaman siap panen rata-rata 40 batang/ha/tahun; 6). Produktivitas $300 \mathrm{~kg}$ tepung kering/batang; 7). Harga tepung sagu kering di tingkat petani Rp 4.000/kg; 8). Diskon faktor pada tingkat bunga $10 \%$ (tingkat bunga pinjaman untuk UMKM); 9). Jangka waktu proyek 25 tahun. Hasil analisis kelayakan usahatani tanaman sagu seperti terlihat pada Tabel 2. 
Tabel 2. Hasil Analisis Kelayakan Usahatani Sagu pada Lahan Gambut

\begin{tabular}{lcc}
\hline \multicolumn{1}{c}{ Aspek yang Dianalisis } & KriteriaKelayakan & HasilAnalisis \\
\hline NPV $($ Rp) & $>0$ & 284.969 .043 \\
B/C ratio & $>1$ & 4,84 \\
IRR $(\%)$ & $>10$ & 31.31 \\
Payback Period (th) & $<25$ & 10 \\
\hline
\end{tabular}

Sumber: Data primer yang diolah.

Berdasarkan hasil analisis kelayakan usahatani seperti terlihat pada Tabel 2, terbukti bahwa usahatani tanaman sagu secara bisnis layak diusahakan dengan nilai $N P V$ sebesar Rp 284.969.03, B/C Ratio sebesar 4,84, IRR sebesar 31,3\% dan masa kembali modal (Payback Period) pada tahun ke-10, atau tahun kedua setelah tanaman menghasilkan. Kelebihan usahatani sagu dibanding usahatani lainnya, misalnya kelapa sawit pada lahan gambut adalah total investasi awal jauh lebih kecil dan produktivitasnya lebih besar serta kontinu. Sehingga benar bahwa usahatani tanaman sagu lebih efisien dibanding komoditas perkebunan lainnya.

\section{KESIMPULAN DAN SARAN}

\section{Kesimpulan}

1. Secara alami pohon sagu dapat tumbuh dengan baik pada kawasan lahan gambut, karena secara teknis dan agroklimat kawasan lahan gambut memang merupakan habitat yang ideal untuk pertumbuhan pohon sagu. Budidaya tanaman sagu pada lahan rawa dan gambut membawa dampak positif, karena secara ekologis sagu memiliki kemampuan menyimpan air, sehingga cocok digunakan dalam upaya memulihkan/merestorasi lahan gambut yang rusak. Kelebihan lain dari segi teknis pada tanaman sagu yanag diusahakan pada lahan gambut adalah bahwa jenis tanaman ini tahan terhadap genangan asal tidak permanen, sehingga untuk budidaya tanaman sagu di lahan gambut tidak harus dibuat saluran drainase yang terlalu dalam.
Dengan demikian dapat dihindari pengatusan yang berlebihan pada lahan gambut, dengan perkataan lain tingkat kebasahan pada lahan gambut tersebut masih tetap terjaga, sehingga lahan gambut mudah terbakar dan memperlambat subsidensi pada lahan gambut tersebut.

2. Hasil analisis kelayakan pada usahatani tanaman sagu menunjukkan bahwa secara bisnis usahatani tanaman sagu layak diusahakan (feasible) dan tidak kalah jika dibanding tanaman perkebunan lainnya, misalnya kelapa sawit. Dengan praktik budidaya yang baik, tanaman sagu dapat menghasilkan produksi tepung sagu yang tinggi, mencapai 20-40 ton pati kering/haper tahun. Pati sagu bermanfaat bagi manusia antara lain sebagai bahan pangan potensial, bahan pakan ternak, bahan bakar hayati (bioetanol), dan bahan baku industri. Industri yang berbahan baku sagu ini sangat beragam antara lain industri gula cair, penyedap makanan, perekat (lem), tekstil, dan industri makanan seperti mie, tepung, kue kering/basah.

\section{Saran}

Permasalahan yang mungkin muncul terkait dengan usahatani tanaman sagu oleh petani, apabila usaha tanaman sagu ini dilakukan dalam skala besar yang melibatkan banyak petani adalah pada aspek pemasaran. Untuk mengatasi masalah ini perlu dipertimbangkan implementasi konsep kemitraan antara petani pekebun dengan perusahaan besar swasta yang bergerak pada agribisnis sagu, 
mengingat sudah ada beberapa perusahaan besar swasta yang bergerak dalam agribisnis sagu, seperti PT. Austindo Nusantara Jaya Tbk, PT. Sampoerna Agro Tbk, Perum Perhutani, PT. National Sago Prima, PT. National Timber and Forest Product, dan lain-lain yang berorientasi ekspor. Dengan pengembangan agribisnis sagu baik oleh petani maupun oleh perusahaan besar swasta tersebut akan terwujud upaya restorasi dan konservasi lahan gambut dengan mempertimbangkan aspek produksi dan kesejahteraan masyarakat sebagaimana diharapkan.

\section{DAFTAR PUSTAKA}

Anonim. (2011). Budidaya Tanaman Sagu.

http://budidayanews.blogspot.co.id

Diakses tanggal 17 Maret 2017.

Asmono, Dwi. (2015). Sampoerna Agro Pioner Sagu di Indonesia. http://agro.kemenperin.go.id Diakses tanggal 17 Maret 2017.

Jayanti, Yanti. 2011.Pengelolaan Budidaya Sagu (Metroxylon spp.) di PT. National Sago Prima, Selat Panjang, Riau dengan Aspek Khusus Pemangkasan dan Aplikasi Hormon Organik pada PetiolBibit Sagu di Persemaian. http://repository.ipb.ac.id/ Diakses tanggal 16 Maret 2017.

Kementerian Pertanian Republik Indonesia. (2013). Pedoman Budidaya Sagu (Metroxylon Spp) yang Baik. Lampiran Peraturan Menteri Pertanian Republik Indonesia Nomor 134/Permentan/OT.140/12/2013 tentang Pedoman Budidaya Sagu (Metroxylon Spp) yang Baik.

Kementerian Sekretariat Negara Republik Indonesia. (2016). Peraturan Presiden Republik Indonesia Nomor 1 Tahun 2016 tentang Badan Restorasi Gambut.
Lembaran Negara Republik Indonesia Tahun 2016 Nomor 1.

Maas, Azwar.(2002). Lahan Rawa Sebagai Lahan Pertanian Kini dan Masa Depan. Prosiding Seminar Nasional Pertanian Lahan Kering dan Lahan Rawa di Banjarbaru, 18 - 19 Desember 2002. Jakarta: Pusat Penelitian dan Pengembangan Sosial Ekonomi Pertanian Badan Litbang Pertanian.

Nazir, Foead. (2016). BRG Berencana Tanam Sagu Untuk Restorasi Lahan Gambut. http://bisnis.com Diakses 20 Maret 2017.

Noor, Muhammad. (2001). Pertanian Lahan Gambut. Potensi dan Kendala. Yogyakarta: Penerbit Kanisius.

Nurhaedah, M. (2014). Manfaat Sagu (Metroxylon Spp.) Bagi Petani Hutan Rakyat di Kabupaten Konawe Selatan. Info Teknis EBONI 11 (2): 9-102.

Radjagukguk, Bostang. (2000). Perubahan Sifat-Sifat Fisik dan Kimia Tanah Gambut Akibat Reklamasi Lahan Gambut untuk Pertanian. Jurnal Ilmu Tanah dan Lingkungan 2 (1): 1-15.

Syakir, M dan Karmawaty, Elna. (2013). Potensi Tanaman Sagu Sebagai Bahan Baku Bioenergi. Perspektif 12 (2): 57-64.

Subiayanto, Bambang. (2016). Tanaman Sagu Bantu Restorasi Lahan Gambut. Biro Kerja sama, Hukum, dan Humas LIPI http://www.antaranews.com Diakses tanggal 17 Maret 2016.

Timisela, Natelda R. (2006). Analisis Usaha Sagu Rumah Tangga dan Pemasarannya. Jurnal Agroforestri 1(3): 58-64. https://www.researchgate.net/public ation/298698070 Diakses tanggal 16 Maret 2017. 
Yoandestina. (2014). Sagu Cocok di Lahan Gambut.

www.balitra.litbang.pertanian.go.id Diakses tanggal 16 Maret 2017. 
Lampiran 1. Analisis IRR

\begin{tabular}{|c|c|c|c|c|c|}
\hline Thn. & Benefit & Cost & DF $31,31 \%$ & PVB & PVC \\
\hline 0 & - & $23,689,000$ & 1.00000000 & - & $23,689,000$ \\
\hline 1 & - & $1,631,800$ & 0.76155662 & - & $1,242,708$ \\
\hline 2 & - & $2,218,600$ & 0.57996849 & - & $1,286,718$ \\
\hline 3 & - & $1,993,400$ & 0.44167884 & - & 880,443 \\
\hline 4 & - & $2,873,500$ & 0.33636345 & - & 966,540 \\
\hline 5 & - & $3,661,000$ & 0.25615981 & - & 937,801 \\
\hline 6 & - & $3,542,300$ & 0.19508020 & - & 691,033 \\
\hline 7 & - & $4,630,500$ & 0.14856462 & - & 687,928 \\
\hline 8 & - & $4,223,600$ & 0.11314037 & - & 477,860 \\
\hline$\underline{9}$ & $96,000,000$ & $13,130,700$ & 0.08616280 & $8,271,629$ & $1,131,378$ \\
\hline 10 & $96,000,000$ & $8,130,700$ & 0.06561785 & $6,299,313$ & 533,519 \\
\hline 11 & $96,000,000$ & $8,130,700$ & 0.04997171 & $4,797,284$ & 406,305 \\
\hline 12 & $96,000,000$ & $8,130,700$ & 0.03805628 & $3,653,403$ & 309,424 \\
\hline 13 & $96,000,000$ & $8,130,700$ & 0.02898202 & $2,782,273$ & 235,644 \\
\hline 14 & $96,000,000$ & $13,130,700$ & 0.02207145 & $2,118,859$ & 289,814 \\
\hline 15 & $96,000,000$ & $8,130,700$ & 0.016808656 & $1,613,631$ & 136,666 \\
\hline 16 & $96,000,000$ & $8,130,700$ & 0.01280074 & $1,228,871$ & 104,079 \\
\hline 17 & $96,000,000$ & $8,130,700$ & 0.00974849 & 935,855 & 79,262 \\
\hline 18 & $96,000,000$ & $8,130,700$ & 0.00742403 & 712,707 & 60,363 \\
\hline 19 & $96,000,000$ & $13,130,700$ & 0.00565382 & 542,766 & 74,239 \\
\hline 20 & $96,000,000$ & $8,130,700$ & 0.00430570 & 413,347 & 35,008 \\
\hline 21 & $96,000,000$ & $8,130,700$ & 0.00327904 & 314,787 & 26,661 \\
\hline 22 & $96,000,000$ & $8,130,700$ & 0.00249717 & 239,728 & 20,304 \\
\hline 23 & $96,000,000$ & $8,130,700$ & 0.00190174 & 182,567 & 15,462 \\
\hline 24 & $96,000,000$ & $13,130,700$ & 0.00144828 & 139,035 & 19,017 \\
\hline \multirow[t]{4}{*}{25} & $96,000,000$ & $8,130,700$ & 0.00110295 & 105,883 & 8,968 \\
\hline & & & Total & $34,351,940$ & $34,346,143$ \\
\hline & & & NPV & $\infty 0$ & \\
\hline & & & IRR & $31.31 \%$ & \\
\hline
\end{tabular}

